\title{
Interactions among dendritic cells, macrophages, and epithelial cells in the gut: implications for immune tolerance Maria Rescigno ${ }^{1}$, Uri Lopatin ${ }^{2}$ and Marcello Chieppa ${ }^{1}$
}

\begin{abstract}
The intestine is described as an immune privileged site where immunoregulatory mechanisms simultaneously defend against pathogens, yet preserve tissue homeostasis to avoid immunemediated pathology in response to environmental challenges. Additionally, tolerance to ingested antigens promotes the development of systemic unresponsiveness towards the same antigens. It is increasingly clear that this tolerance is a complex process that derives from the coordinated action of both canonical immune and non-immune cells at mucosal sites, including dendritic cells, macrophages and epithelial cells. Recent evidence suggests that dysregulation in gut-induced tolerance and commensal bacterial handling affects both local and systemic compartments and contributes to autoimmune disease. Understanding how tolerance is achieved at mucosal sites may thus be exploited to re-establish tissue homeostasis.
\end{abstract}

\section{Addresses}

${ }^{1}$ Department of Experimental Oncology, European Institute of Oncology, Milan, Italy

${ }^{2}$ Roche, Clinical Research and Exploratory Development, Palo Alto, CA, USA

Corresponding author: Rescigno, Maria (maria.rescigno@ifom-ieocampus.it)

\section{Current Opinion in Immunology 2008, 20:669-675}

This review comes from a themed issue on

Autoimmunity

Edited by Ciriaco Piccirillo and Roberta Pelanda

Available online 22nd October 2008

$0952-7915 / \$$ - see front matter

(C) 2008 Elsevier Ltd. All rights reserved.

DOI 10.1016/j.coi.2008.09.007

\section{Introduction}

The digestive apparatus is likely the first discrete organ to develop. Nutrients are forced into a 'lumen' to favor absorption. The luminal content is separated from the epithelial cell membrane by a mucous layer [1]. However, this mucous barrier provides imperfect protection against the diversity of bacteria residing in the same luminal content. Thus rich arrays of immune cells are scattered both between epithelial cells (ECs) and deeper in the lamina propria (LP). These cells participate in the discrimination between food and pathogenic organisms, in the induction of $\operatorname{IgA}$ response, and in the inhibition of inflammatory responses to the continuous challenge of intestinal bacteria. Furthermore, commensal bacteria normally considered as safe may become pathogenic and contribute malabsorption, inflammatory bowel disease, and colorectal cancer [2]. How can the intestinal immune system handle this load of information is not completely understood, but it is becoming clear that the interaction between luminal bacteria, epithelial cells, and immune cells is crucial to preserve intestinal homeostasis. In this review, we will focus on three important cell types: epithelial cells, dendritic cells, and macrophages that via a coordinated action help keeping peace at mucosal surfaces but are ready to fight, when needed.

\section{Epithelial cells: not simply a barrier}

Most pathogen recognition receptors, including Toll-like receptors (TLRs), were thought to be exclusively expressed either intracellularly or on the basolateral membrane of epithelial cells, leaving the apical membrane unable to interact with bacteria. Subsequently, several findings suggested that this may not be the case. Rather it has been shown that the binding of TLR ligands can occur both at apical and at basolateral membranes, giving different outcomes [3]. A typical example is TLR9, the receptor for unmethylated $\mathrm{CpG}$-containing bacterial DNA. Unlike myeloid cells, TLR9 is expressed on the cell surface of epithelial cells, both apically and basolaterally, in vitro and in vivo [ $\left.4^{\bullet}\right]$. TLR9 engagement on the apical surface of epithelial cells induces partial activation of $\mathrm{NF}-\kappa \mathrm{B}$, a master regulator of the inflammatory response, without stimulating the release of proinflammatory cytokines (Figure 1). By contrast, basolateral engagement of TLR9 leads to a robust inflammatory response, which can be inhibited by preincubation with apical $\mathrm{CpG}\left[4^{\bullet}\right]$. This suggests that the apical engagement of TLRs is protective. In agreement, mice lacking TLRs or TLR signaling are more prone to develop experimental colitis [5-7]. These experiments also indicate that partial NF- $\mathrm{\kappa B}$ activation is protective rather than inflammatory. In agreement, mice with intestinal epithelial cell deletion of different subunits of IKK, kinases required for NF-кB activation, display severe chronic intestinal inflammation $\left[8^{\bullet \bullet}\right]$ or are more susceptible to infections [ $9^{\bullet \bullet}$. Finally, commensal bacteria were found to interact with epithelial cells and induce inhibitory signals in ECs [10-12]. Incubation of epithelial cells with noninvasive strains of Salmonella enteriditis or Bacteroides thetaiotaomicron leads to the reduction of $\mathrm{NF}-\kappa \mathrm{B}$ activation and translocation to the nucleus [11,13] or premature egress of RelA subunit from the nucleus [10], respectively. Interestingly, reactive oxygen species (ROS) induced by commensals are responsible for the inactivation of the catalytic cysteine residue of Ubc12 


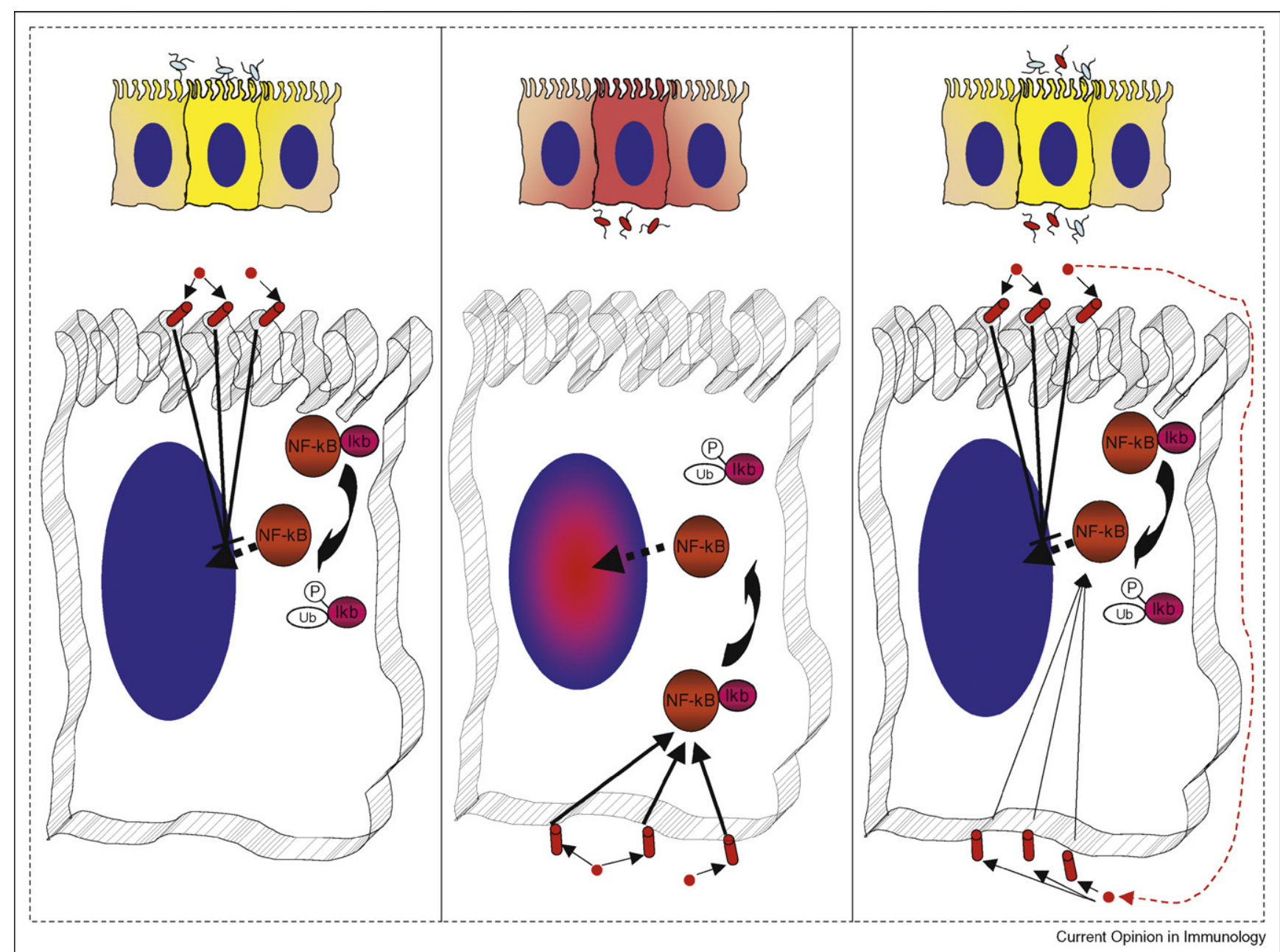

Epithelial cells are not simply a barrier. Three different conditions of epithelial cell (EC) activation are depicted. Unlike myeloid cells, ECs express TLR9 on their cell surface (red cylinders) and respond to bacterial DNA (red circles). During steady state (left panel), ECs sense the presence of commensal bacteria (light blue) and are 'set' to a noninflammatory mode. There is partial activation of NF-кB that does not result in nuclear translocation. During infection (middle panel), invasive bacteria (red) reach the basolateral membrane. Here TLR9 triggering leads to full NF- $\mathrm{B}$ activation and the release of inflammatory mediators. As apical engagement of TLR9 inhibits full activation of NF- $\mathrm{kB}$ from basolateral TLR9 engagement, it is not clear whether ECs under steady state are inflammatory at all (right panel). We hypothesize that ECs located at the tip of the villi are more exposed to bacteria resulting in tolerization, while those located closer to the crypts are in a more 'sterile' environment because of the release of antimicrobial peptides by Paneth cells and retain their inflammatory potential. Invasive bacteria that reach the deeper cells may initiate an inflammatory cascade. Alternatively, in vivo, invasive bacteria could transform the tolerogenic phenotype of ECs, perhaps as a consequence of binding to basolaterally expressed TLRs. These possibilities remain to be explored.

resulting in impaired $\mathrm{I}-\kappa \mathrm{B}$ ubiquitination and $\mathrm{NF}-\kappa \mathrm{B}$ activation $\left[1^{\circ}\right]$. Altogether, these data suggest that epithelial cells are not simply a barrier to intestinal bacteria [15]. It is unclear though if bacteria contact EC surface receptors somehow bypassing the large mucus layer covering the epithelial membrane, or if TLR ligands released during bacterial degradation deliver anti-inflammatory signals. Nonetheless, it appears that as long as the bacteria remain in the lumen they are sensed as innocuous and the result is not ignorance, but induction of a protective tolerogenic response.

\section{Epithelial cells during infection}

In general, pathogenic bacteria are invasive and reach intracellular compartments as well as the basolateral membrane to initiate a proinflammatory signaling cascade [12]. These generate 'alarm' signals to underlying immune cells and recruit circulating leukocytes. However, as mentioned above, if epithelial cells are tolerized by the presence of commensals or bacterial products at their apical surface, how do they respond to invasive bacteria? One possibility is that epithelial cells located at the tip of the villi are more exposed to bacteria resulting in tolerization, while those 


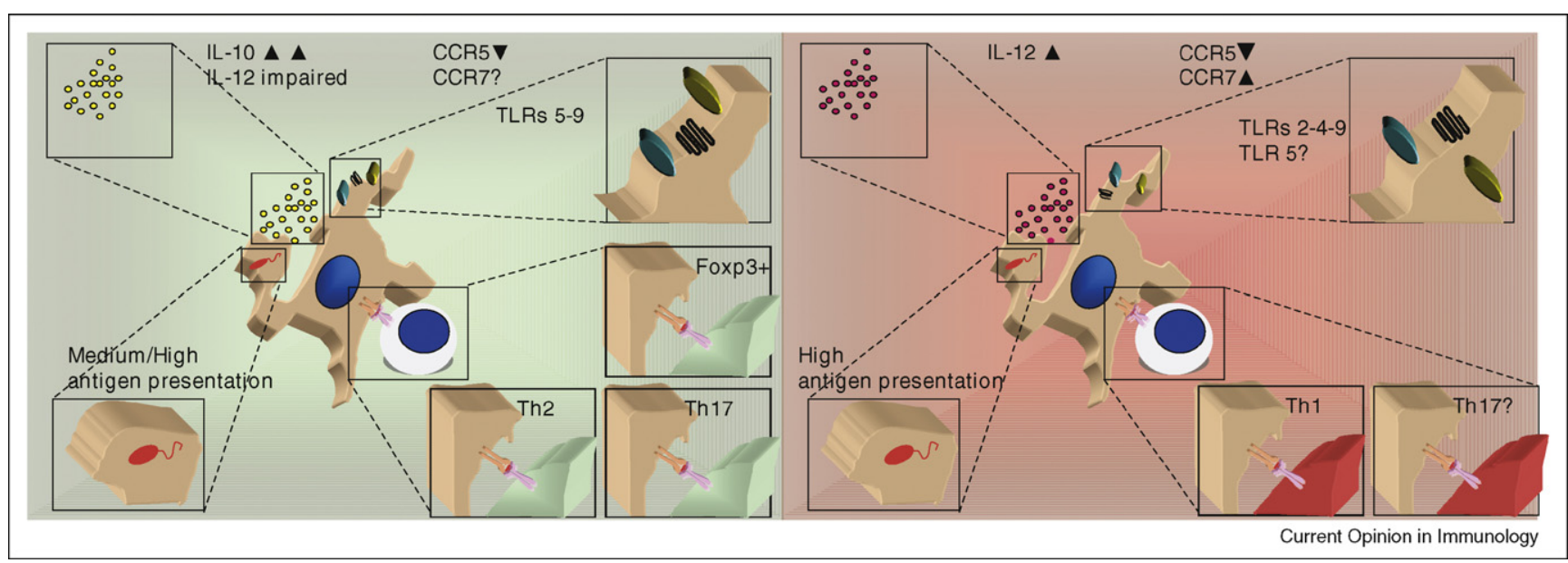

Specialized functions of gut DCs. Resident LP-DCs (left panel) have been shown to be impaired in their ability to release inflammatory cytokines like IL-12, but produce more IL-10. DC precursors $\left(C D 11 b^{10} \mathrm{CD} 11 \mathrm{c}^{10}\right.$ ) express TLRs but are not responsive to TLR ligation, while differentiated DCs express only TLR5 and TLR9, and respond to flagellin. Depending on the analyzed subset, DCs can either induce Th2, Foxp3+ $\mathrm{T}_{\text {regs }}$ or Th17 T cell development. The location and precise phenotype that distinguishes these different subsets remains to be understood. During inflammation (right panel) it is not yet clear whether resident DCs lose their noninflammatory properties, or whether fresh nonconditioned DCs are recruited from blood as differentiated cells or monocytic precursors. The immunostimulatory environment drives their full activation. DCs release IL-12 and drive the development of Th1 T cells. It is not yet clear whether activated cells are better inducers of Th17 T cells.

located closer to the crypts are in a more 'sterile' environment because of the release of antimicrobial peptides by Paneth cells and retain their inflammatory potential. Invasive bacteria that reach the deeper cells may initiate an inflammatory cascade. Alternatively, in vivo, invasive bacteria could transform the tolerogenic phenotype of ECs, perhaps as a consequence of binding to basolaterally expressed TLRs. These possibilities need to be explored, but it has been shown that TLR3 ligation induces severe mucosal injury, suggesting that some apically applied TLR ligands may be inflammatory [16].

\section{Immune cells in the gut}

Peyer's patches (PPs) that represent the major gut-associated lymphoid tissue, differ from other lymphoid organs. They contain a higher proportion of $\mathrm{B}$ cells versus $\mathrm{T}$ cells [17] and are rich in cytokines with IgA-inducing functions, including transforming growth factor (TGF)- $\beta$ [18]. Therefore, PPs are considered a site conducive to antigen-specific IgA induction, as in response to Salmonella [19]. By contrast, PPs are dispensable for the generation of T-cell-independent IgA responses that seem to occur directly in the LP [20]. Dendritic cells (DCs) are professional antigen-presenting cells characterized by the ability to migrate to mesenteric lymph nodes (MLNs) both during the steady state and during infection [21,22]. In the PPs, DCs are located in the subepithelial dome, just below the follicle-associated epithelium, and migrate to $\mathrm{T}$ and $\mathrm{B}$ cell areas after stimulation.

The vast majority of LP is colonized by immune cells. The LP is home to a large number of T regulatory cells, invariant $\mathrm{T}$ cells, natural killer cells and noncanonical CD8 $\alpha \alpha$ intraepithelial $\mathrm{T}$ cells [23,24]. All these cells seem to play a role in protecting against commensaldriven inflammation. This allows a dynamic control of the immune response depending on the external environment. DCs are not only deeply infiltrated into villi but are also in close contact with the intestinal epithelium $[25,26]$. Epithelial TLR engagement provokes DCs to extend processes into the intestinal lumen for direct bacterial uptake $\left[27^{\circ}\right]$.

\section{Gut dendritic cells}

It is becoming clear that there is neither systemic immunity nor tolerance to commensals [28]. Commensal-laden DCs are retained in MLNs and do not reach the spleen, thus impeding the induction of commensal-specific systemic IgG responses [29]. As anticipated, a key requirement of the intestinal immune system is to generate oral tolerance to food antigen, while preserving immunity to pathogens. A major site for this process is MLN [30]. Within the MLN, DCs are potent mediators of tolerogenic and inflammatory phenomena. A population of DCs characterized by the expression of CD103 has been described to have the ability to induce the de novo differentiation of naïve $\mathrm{T}$ cells into CD4+CD25+Foxp3+ T cells, via a TGF $-\beta$ and retinoic acid (RA)-dependent mechanism [31 $\left.{ }^{\bullet \bullet}\right]$. This population is presumably coming from the LP $\left[32^{\bullet \bullet}, 33\right]$.

Also DCs from other gut district display specialized functions [34,35] (Figure 2). LP-DCs express only TLR5 and TLR9 and induce IgA class switching and 


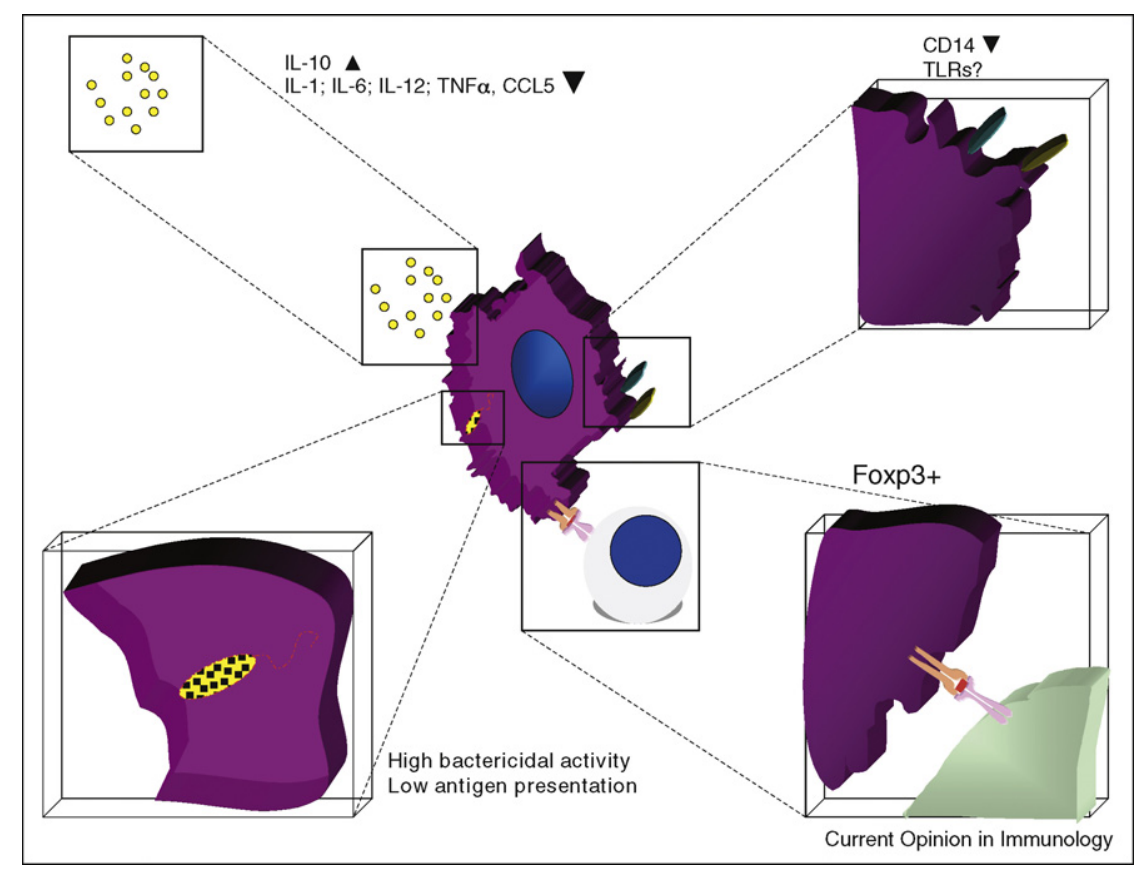

Specialized functions of gut macrophages. Macrophages isolated from the gut are impaired in the release of proinflammatory mediators in response to bacteria, but retain their bactericidal activity. Intestinal macrophages also have reduced CD14 surface expression and selective TLR expression. Macrophages can also release TGF- $\beta$ and retinoic acid and drive the development of Foxp3 $+T_{\text {regs }}$. Recently, a population of cells with intermediate phenotype between macrophages and DCs has also been described.

Th17 cells when challenged, however the clinical consequence of this response is unclear $\left[36^{\bullet}, 37\right]$. A subpopulation of LP-DCs $\left(\mathrm{CD} 11 \mathrm{~b}^{\mathrm{lo}} \mathrm{CD} 11 \mathrm{c}^{\mathrm{lo}}\right)$ although expressing high levels of TLRs fails to produce proinflammatory cytokines when challenged [ $\left.38^{\circ}\right]$. This explains why the capacity of DCs to extend dendrites across the intestinal lumen depends on TLR engagement on epithelial cells and not on DCs $\left[27^{\circ}\right]$.

Finally, PP-DCs can impart gut-homing properties to T cells, $\mathrm{B}$ cells, and $\mathrm{T}_{\text {regs }}$ via a RA-dependent mechanism $\left[33,39,40,41^{\circ}, 42\right]$. PP-DCs can also drive IgA class switching via a RA-dependent mechanism $\left[41^{\circ}, 43\right]$.

\section{Macrophages}

Macrophages display specialized functions in the gut in a fashion similar to DCs (Figure 3). Macrophages also display selective expression of TLRs, and are unresponsive to TLR ligation in terms of proinflammatory cytokine production, but retain fully competent bactericidal activity [44]. Recently, a new function for intestinal macrophages has been proposed. Like CD103+ DCs, they have been shown to support the induction of $\mathrm{CD} 4+\mathrm{CD} 25+\mathrm{Foxp} 3+\mathrm{T}_{\text {reg }}$ cells $\left[45^{\circ}\right]$. The function of tolerogenic macrophages is not clear, as it is not known whether they can migrate to MLN. However, cell migration to MLN has been shown to be required for the induction of oral tolerance [30]. One hypothesis is that macrophages support locally the maintenance of a $T_{\text {reg }}$ phenotype in an environment continuously exposed to bacteria and bacterial products. Macrophages have also been described to tune DC function by inhibiting their potential to drive Th17 T cells [45 ${ }^{\circ}$. A unique CD14+ inflammatory cell with intermediate phenotype between DCs and macrophages has also been recently described in the human gut [46]. This cell type could represent a recently recruited monocyte that is undergoing a transition to either macrophages or DCs.

\section{Epithelial cell-dendritic cell-macrophage interactions}

The previous observations indicate that intestinal epithelial cells, DCs, and macrophages are profoundly noninflammatory. This state is characterized by the inability of these cell types to initiate inflammatory responses to intestinal bacteria. However, these intestinal immune cells are not paralyzed and bacteria are not ignored. For instance, commensal reactive IgAs are found in mice reared under specific pathogen-free conditions [47]. These IgAs could be either specific or polyreactive and serve as anchors, which may either prevent internalization or promote a controlled entrance of bacteria via $\mathrm{M}$ cells [48]. Gut DCs also have the peculiar capacity to induce $\mathrm{T}_{\text {reg }}$ cell development; however, there is no systemic 


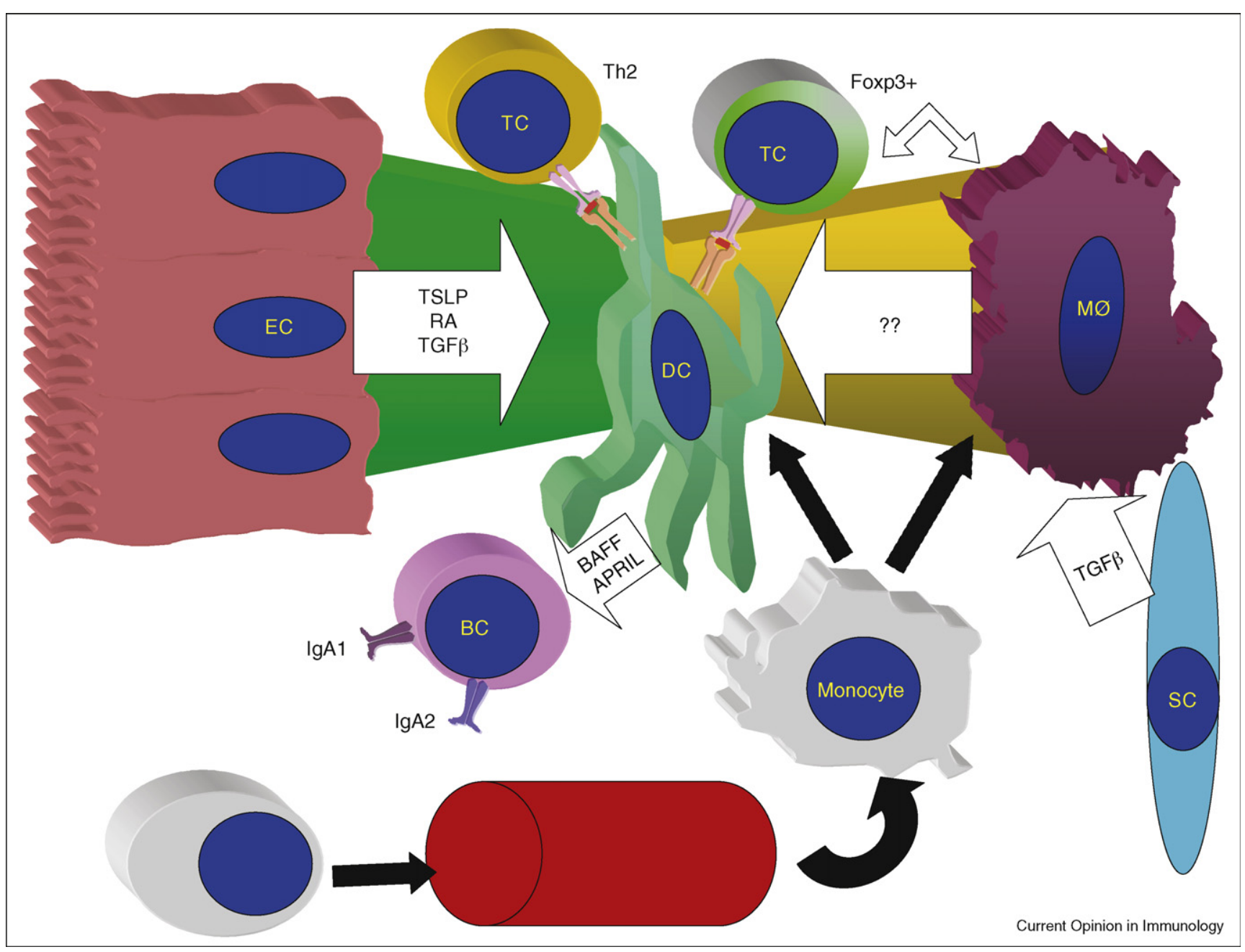

Epithelial cell-dendritic cell-macrophage interactions. What drives the development of the specialized functions of gut DCs? Human intestinal epithelial cells release TSLP, TGF- $\beta$, and RA that drive the development of tolerogenic DCs able to induce Th2 and Foxp3+ $T_{\text {regs }}$. TSLP is also shown to favor the release of BAFF and APRIL by conditioned DCs and supports IgA class switching of B cells directly in the LP or the generation of protease-resistant IgA2 after sequential class switching from IgA1. Additionally, macrophages appear to tune the inflammatory potential of DCs, but the factors involved are not yet known. On the other hand, macrophages are shaped by stromal cell derived TGF- $\beta$ and induce Foxp3+ $T_{\text {regs }}$ in a fashion similar to DCs. DCs and macrophages derive from circulating monocytes that could undergo 'mucosal' conditioning during their terminal differentiation into the tissue. In agreement, $T_{\text {regs }}$ can steer the differentiation of monocytes into regulatory macrophages. Hence, the concerted action of immune cells, stromal cells, and epithelial cells is required to keep peace at intestinal surfaces.

tolerance to commensal bacteria. One might argue that these $\mathrm{T}_{\text {regs }}$ are retained within the gut without spreading to systemic districts, as would be hypothesized by the expression of gut-homing receptors [42]. Alternatively, $\mathrm{T}_{\text {regs }}$ specific for commensal bacteria are not generated. These issues remain to be elucidated (Figure 4).

What drives the development of the specialized functions of gut DCs? We hypothesize that the local microenvironment, and in particular intestinal epithelial cells, plays a role in shaping DC function. The simple incubation of human monocyte derived DCs with epithelial cell supernatant is sufficient to induce a 'mucosal' phenotype to
DCs [49]. Epithelial cell conditioned DCs are unable to release inflammatory cytokines and to drive Th1 T cells. In humans, thymic stromal lymphopoietin (TSLP) was identified as one of the conditioning factors released by epithelial cells [49]. Interestingly, TSLP is also shown to favor the release of BAFF and APRIL by conditioned DCs and supports IgA class switching of B cells directly in the LP [50], or the generation of protease-resistant IgA2 after sequential class switching from IgA1 [51 $\left.{ }^{\bullet \bullet}\right]$. TSLP is not the only factor released by epithelial cells that confers mucosal DC properties. Both mouse and human epithelial cells also release RA and TGF- $\beta$. These factors are required to drive the development of CD103+ tolerogenic 
DCs (Iliev et al., unpublished). Epithelial cells are not the only cells able to modulate DC function. As mentioned above, macrophages also appear to tune the inflammatory potential of DCs $\left[45^{\circ}\right]$. Further, macrophages are shaped by stromal cell-derived TGF- $\beta$ [44] and by $\mathrm{T}_{\text {regs }}$ that direct their differentiation from monocytes into anti-inflammatory cells [52]. Altogether these findings suggest that the reciprocal action of immune cells, stromal cells, and epithelial cells is required to keep peace at intestinal surfaces.

\section{Conclusions}

In conclusion, intestinal resident immune cells have been shown to display specialized functions aimed at maintaining immune homeostasis. These cells interact and control the reciprocal function of the others. Epithelial cells, in particular, both at steady state and during infection sense the external world and relay this information to underlying immune cells. These interactions can lead either to tolerogenic or to inflammatory immune responses depending on the local status of the intestine. As our knowledge of these players expands, we may understand the contribution of other components like intraepithelial lymphocytes, mast cells, stromal cells, and glial cells in the overall immune homeostasis.

\section{Acknowledgements}

MR is supported by European Commission grants METAhit, ERC, and IBDase, by the Crohn's and Colitis Foundation of America (CCFA), and by the Associazione Italiana per la Ricerca sul Cancro (AIRC). MC is supported by a Marie-Curie reintegration grant.

\section{References and recommended reading}

Papers of particular interest, published within the period of the review, have been highlighted as

- of special interest

$\bullet$ of outstanding interest

1. Atuma C, Strugala V, Allen A, Holm L: The adherent gastrointestinal mucus gel layer: thickness and physical state in vivo. Am J Physiol Gastrointest Liver Physiol 2001, 280:G922-G929.

2. Rescigno $M$ : The pathogenic role of intestinal flora in IBD and colon cancer. Curr Drug Targets 2008, 9:395-403.

3. Lee J, Gonzales-Navajas JM, Raz E: The "polarizing-tolerizing" mechanism of intestinal epithelium: its relevance to colonic homeostasis. Semin Immunopathol 2008, 30:3-9.

4. Lee J, Mo JH, Katakura K, Alkalay I, Rucker AN, Liu YT, Lee HK,

- Shen C, Cojocaru G, Shenouda S et al.: Maintenance of colonic homeostasis by distinctive apical TLR9 signalling in intestinal epithelial cells. Nat Cell Biol 2006, 8:1327-1336.

This manuscript clearly demonstrates that TLR9 can be expressed on the apical surface and participates in inhibiting inflammation.

5. Rakoff-Nahoum S, Paglino J, Eslami-Varzaneh F, Edberg S, Medzhitov R: Recognition of commensal microflora by toll-like receptors is required for intestinal homeostasis. Cell 2004, 118:229-241.

6. Fukata M, Michelsen KS, Eri R, Thomas LS, Hu B, Lukasek K, Nast CC, Lechago J, Xu R, Naiki Y et al.: Toll-like receptor-4 is required for intestinal response to epithelial injury and limiting bacterial translocation in a murine model of acute colitis. $A m \mathrm{~J}$ Physiol Gastrointest Liver Physiol 2005, 288:G1055-G1065.

7. Cario E, Gerken G, Podolsky DK: Toll-like receptor 2 controls mucosal inflammation by regulating epithelial barrier function. Gastroenterology 2007, 132:1359-1374.
8. Nenci A, Becker C, Wullaert A, Gareus R, van Loo G, Danese S

- Huth M, Nikolaev A, Neufert C, Madison B et al.: Epithelial NEMO links innate immunity to chronic intestinal inflammation. Nature 2007, 446:557-561.

See annotation to Ref. [9].

9. Zaph C, Troy AE, Taylor BC, Berman-Booty LD, Guild KJ, Du Y

-. Yost EA, Gruber AD, May MJ, Greten FR et al.: Epithelial-cellintrinsic IKK-beta expression regulates intestinal immune homeostasis. Nature 2007, 446:552-556.

The above papers are the first example that NF- $\mathrm{B}$ signaling exclusively in epithelial cells is required to maintain gut immune homeostasis.

10. Kelly D, Campbell JI, King TP, Grant G, Jansson EA, Coutts AG, Pettersson S, Conway S: Commensal anaerobic gut bacteria attenuate inflammation by regulating nuclear-cytoplasmic shuttling of PPAR-gamma and RelA. Nat Immunol 2004, 5:104-112.

11. Neish AS, Gewirtz AT, Zeng H, Young AN, Hobert ME, Karmali V Rao AS, Madara JL: Prokaryotic regulation of epithelial responses by inhibition of IkappaB-alpha ubiquitination. Science 2000, 289:1560-1563.

12. Sansonetti PJ: War and peace at mucosal surfaces. Nat Rev Immunol 2004, 4:953-964.

13. Tien MT, Girardin SE, Regnault B, Le Bourhis L, Dillies MA, Coppee JY, Bourdet-Sicard R, Sansonetti PJ, Pedron T: Anti-inflammatory effect of Lactobacillus casei on Shigellainfected human intestinal epithelial cells. J Immunol 2006 176:1228-1237.

14. Kumar A, Wu H, Collier-Hyams LS, Hansen JM, Li T, Yamoah K - Pan ZQ, Jones DP, Neish AS: Commensal bacteria modulate cullin-dependent signaling via generation of reactive oxygen species. EMBO J 2007, 26:4457-4466.

In this manuscript it is shown that commensal bacteria induce a reactive oxygen species (ROS) burst that controls the activity of cullin and the degradation of $\mathrm{I}-\mathrm{\kappa} \mathrm{B}$.

15. Artis D: Epithelial-cell recognition of commensal bacteria and maintenance of immune homeostasis in the gut. Nat Rev Immunol 2008, 8:411-420.

16. Zhou R, Wei H, Sun R, Tian Z: Recognition of double-stranded RNA by TLR3 induces severe small intestinal injury in mice. $J$ Immunol 2007, 178:4548-4556.

17. Stevens SK, Weissman IL, Butcher EC: Differences in the migration of $B$ and $T$ lymphocytes: organ-selective localization in vivo and the role of lymphocyteendothelial cell recognition. J Immunol 1982 128:844-851.

18. Gonnella PA, Chen Y, Inobe J, Komagata Y, Quartulli M, Weiner HL: In situ immune response in gut-associated lymphoid tissue (GALT) following oral antigen in TCRtransgenic mice. J Immunol 1998, 160:4708-4718.

19. Martinoli C, Chiavelli A, Rescigno M: Entry route of Salmonella typhimurium directs the type of induced immune response. Immunity 2007, 27:975-984.

20. Cerutti A: The regulation of IgA class switching. Nat Rev Immunol 2008, 8:421-434.

21. Huang FP, Platt N, Wykes M, Major JR, Powell TJ, Jenkins CD, MacPherson GG: A discrete subpopulation of dendritic cells transports apoptotic intestinal epithelial cells to $\mathrm{T}$ cell areas of mesenteric lymph nodes [see comments]. J Exp Med 2000, 191:435-444.

22. Turnbull EL, Yrlid U, Jenkins CD, Macpherson GG: Intestinal dendritic cell subsets: differential effects of systemic TLR4 stimulation on migratory fate and activation in vivo. $\mathrm{J}$ Immunol 2005, 174:1374-1384.

23. Treiner E, Lantz O: CD1d- and MR1-restricted invariant T cells: of mice and men. Curr Opin Immunol 2006, 18:519-526.

24. Kunisawa J, Takahashi I, Kiyono H: Intraepithelial lymphocytes: their shared and divergent immunological behaviors in the small and large intestine. Immunol Rev 2007, 215:136-153. 
25. Rescigno M, Urbano M, Valzasina B, Francolini M, Rotta G, Bonasio R, Granucci F, Kraehenbuhl JP, Ricciardi-Castagnoli P: Dendritic cells express tight junction proteins and penetrate gut epithelial monolayers to sample bacteria. Nat Immunol 2001, 2:361-367.

26. Niess JH, Brand S, Gu X, Landsman L, Jung S, McCormick BA, Vyas JM, Boes M, Ploegh HL, Fox JG et al.: CX3CR1-mediated dendritic cell access to the intestinal lumen and bacterial clearance. Science 2005, 307:254-258.

27. Chieppa M, Rescigno M, Huang AY, Germain RN: Dynamic

- imaging of dendritic cell extension into the small bowel lumen in response to epithelial cell TLR engagement. J Exp Med 2006, 203:2841-2852.

It was not clear what drives the extensions of DCs into the intestinal lumen. In this manuscript, the authors show the requirement of TLR signaling in epithelial cells and not in DCs.

28. Macpherson AJ, Slack $E$ : The functional interactions of commensal bacteria with intestinal secretory IgA. Curr Opin Gastroenterol 2007, 23:673-678.

29. Macpherson AJ, Uhr T: Induction of protective IgA by intestinal dendritic cells carrying commensal bacteria. Science 2004 303:1662-1665.

30. Worbs T, Bode U, Yan S, Hoffmann MW, Hintzen G, Bernhardt G, Forster R, Pabst O: Oral tolerance originates in the intestinal immune system and relies on antigen carriage by dendritic cells. J Exp Med 2006, 203:519-527.

31. Coombes JL, Siddiqui KR, Arancibia-Carcamo CV, Hall J, Sun CM,

- Belkaid Y, Powrie F: A functionally specialized population of mucosal CD103+ DCs induces Foxp3+ regulatory T cells via a TGF-\{beta\} and retinoic acid dependent mechanism. $J$ Exp Med 2007, 204:1757-1764.

See annotation to Ref. [32**].

32. Sun JB, Raghavan S, Sjoling A, Lundin S, Holmgren J: Oral

-. tolerance induction with antigen conjugated to cholera toxin $B$ subunit generates both Foxp3+CD25+ and Foxp3-CD25CD4+ regulatory T cells. J Immunol 2006, 177:7634-7644.

For the first time the ability of intestinal DCs to drive de novo Foxp3+CD25+ $T$ cell differentiation was described in the above manuscripts.

33. Johansson-Lindbom $B$, Svensson $M$, Pabst $O$, Palmqvist $C$, Marquez G, Forster R, Agace WW: Functional specialization of gut CD103+ dendritic cells in the regulation of tissue-selective T cell homing. J Exp Med 2005, 202:1063-1073.

34. Iwasaki A: Mucosal dendritic cells. Annu Rev Immunol 2007, 25:381-418.

35. Coombes JL, Powrie F: Dendritic cells in intestinal immune regulation. Nat Rev Immunol 2008, 8:435-446.

36. Uematsu S, Fujimoto K, Jang MH, Yang BG, Jung YJ,

- Nishiyama M, Sato S, Tsujimura T, Yamamoto M, Yokota Y et al.: Regulation of humoral and cellular gut immunity by lamina propria dendritic cells expressing Toll-like receptor 5 . Nat Immunol 2008, 9:769-776.

In this manuscript LP-DCs are shown to drive IgA class switching in a retinoic acid-dependent fashion.

37. Uematsu S, Jang MH, Chevrier N, Guo Z, Kumagai $Y$, Yamamoto M, Kato $\mathrm{H}$, Sougawa $\mathrm{N}$, Matsui $\mathrm{H}$, Kuwata $\mathrm{H}$ et al.: Detection of pathogenic intestinal bacteria by Toll-like receptor 5 on intestinal CD11c+ lamina propria cells. Nat Immunol 2006, 7:868-874.

38. Monteleone I, Platt AM, Jaensson E, Agace WW, Mowat AM: IL-

- 10-dependent partial refractoriness to Toll-like receptor stimulation modulates gut mucosal dendritic cell function. Eur $J$ Immunol 2008, 38:1533-1547.

The authors show that LP-DCs either do not express most TLRs or are unresponsive to their ligands.
39. Stagg AJ, Kamm MA, Knight SC: Intestinal dendritic cells increase $T$ cell expression of alpha4beta7 integrin. Eur J Immunol 2002, 32:1445-1454.

40. Mora JR, Bono MR, Manjunath N, Weninger W, Cavanagh LL, Rosemblatt M, Von Andrian UH: Selective imprinting of guthoming T cells by Peyer's patch dendritic cells. Nature 2003 424:88-93.

41. Mora JR, Iwata M, Eksteen B, Song SY, Junt T, Senman B,

- Otipoby KL, Yokota A, Takeuchi H, Ricciardi-Castagnoli P et al.: Generation of gut-homing IgA-secreting B cells by intestinal dendritic cells. Science 2006, 314:1157-1160.

In this manuscript PP-DCs were shown to preferentially induce guthoming IgA producing $B$ cells.

42. Benson MJ, Pino-Lagos K, Rosemblatt M, Noelle RJ: All-trans retinoic acid mediates enhanced $T$ reg cell growth, differentiation, and gut homing in the face of high levels of costimulation. J Exp Med 2007, 204:1765-1774.

43. Sato A, Hashiguchi M, Toda E, Iwasaki A, Hachimura S, Kaminogawa S: CD11b+ Peyer's patch dendritic cells secrete IL-6 and induce IgA secretion from naive B cells. J Immunol 2003, 171:3684-3690.

44. Smythies LE, Sellers M, Clements RH, Mosteller-Barnum M, Meng G, Benjamin WH, Orenstein JM, Smith PD: Human intestinal macrophages display profound inflammatory anergy despite avid phagocytic and bacteriocidal activity. J Clin Invest 2005, 115:66-75.

45. Denning TL, Wang YC, Patel SR, Williams IR, Pulendran B: Lamina

- propria macrophages and dendritic cells differentially induce regulatory and interleukin 17-producing $\mathrm{T}$ cell responses. Nat Immunol 2007, 8:1086-1094.

A new function of intestinal macrophages in inducing $T_{\text {reg }}$ cells and in tuning DC function has been demonstrated.

46. Kamada N, Hisamatsu $T$, Okamoto $S$, Chinen $H$, Kobayashi $T$, Sato T, Sakuraba A, Kitazume MT, Sugita A, Koganei K et al.: Unique CD14 intestinal macrophages contribute to the pathogenesis of Crohn disease via IL-23/IFN-gamma axis. $J$ Clin Invest 2008, 118:2269-2280.

47. Macpherson AJ, Gatto D, Sainsbury E, Harriman GR Hengartner $H$, Zinkernagel RM: A primitive T cell-independent mechanism of intestinal mucosal IgA responses to commensal bacteria. Science 2000, 288:2222-2226.

48. Corthesy B: Roundtrip ticket for secretory IgA: role in mucosal homeostasis? J Immunol 2007, 178:27-32.

49. Rimoldi M, Chieppa M, Salucci V, Avogadri F, Sonzogni A, Sampietro GM, Nespoli A, Viale G, Allavena P, Rescigno M: Intestinal immune homeostasis is regulated by the crosstalk between epithelial cells and dendritic cells. Nat Immunol 2005, 6:507-514.

50. Xu W, He B, Chiu A, Chadburn A, Shan M, Buldys M, Ding A, Knowles DM, Santini PA, Cerutti A: Epithelial cells trigger frontline immunoglobulin class switching through a pathway regulated by the inhibitor SLPI. Nat Immunol 2007, 8:294-303.

51. He B, Xu W, Santini PA, Polydorides AD, Chiu A, Estrella J, Shan M,

-• Chadburn A, Villanacci V, Plebani A et al.: Intestinal bacteria trigger $T$ cell-independent immunoglobulin $A(2)$ class switching by inducing epithelial-cell secretion of the cytokine APRIL. Immunity 2007, 26:812-826.

In the above manuscripts the authors have clearly shown that epithelia cells play a major role in controlling lgA-class switching directly in the lamina propria and to drive the sequential switch of $\lg A 1$ to proteaseresistant IgA2.

52. Tiemessen MM, Jagger AL, Evans HG, van Herwijnen MJ, John S, Taams LS: CD4+CD25+Foxp3+ regulatory $T$ cells induce alternative activation of human monocytes/macrophages. Proc Natl Acad Sci U S A 2007, 104:19446-19451. 